2. Silica glass is similarly permeable to helium. This may be easily measured at $180^{\circ}$. At $500^{\circ}$ this permeability is about 22 times that of hydrogen.

3. Neither Pyrex glass nor Jena combustion glass was found to be permeable to hydrogen, but the gas apparently reacts with the Pyrex, causing it to blacken. The latter is also permeable to helium.

4. The permeabilities of a number of samples of glass were determined and the results correlated with the work of previous experimenters.

Toronto, Canada

[CONTRIBUtion From the Defartment OF Chemistry of PuRdue University ] THE DETERMINATION OF LEAD IN LEAD AMALGAM

By M. G. MELLION

Received July 1, 1922

The determination of lead in lead amalgam, or of both the lead and the mercury, has been accomplished by several methods. A brief account of the types of these methods which have been so employed was presented in a preliminary paper. ${ }^{1}$ At this time it seems sufficient to mention merely the principles involved in the various procedures.

Two electrolytic methods have been proposed. For amalgams prepared electrolytically Lindeck ${ }^{2}$ and Stähler and Alders ${ }^{3}$ claim success in the calculation of the concentration of the lead from the weights of mercury used as cathode and of the resulting amalgam. Vortmann ${ }^{4}$ reported difficulty from oxidation of the amalgam while drying, and the author has had the same experience. Smith ${ }^{5}$ reported the simultaneous electrodeposition of small amounts of lead and mercury from a solution in nitric acid.

The gravimetric procedures involve a solution of the amalgam in nitric acid and a subsequent separation of the two elements by precipitation. The lead may be precipitated by means of sulfuric acid and the mercury taken by difference, or determined as the sulfide. ${ }^{6} \quad$ Humphreys volatilized a considerable portion of the mercury before dissolving the amalgam. Treadwell, ${ }^{7}$ and also Scott, ${ }^{8}$ recommend precipitating the two elements together as the sulfides and then effecting a later separation.

${ }^{1}$ Mellon and Reinhard, Proc. Ind. Acad. Sci., 1921, p. 189.

${ }^{2}$ Lindeck, Wied. Ann., 35, 311 (1888).

${ }^{3}$ Stähler and Alders, Ber., 42, 2685 (1909).

${ }^{4}$ Vortmann, ibid., 22, 2756 (1891).

${ }^{5}$ Smith and Moyer, J. Anal. Chem., 7, 252 (1893). Smith and Heidenreich, Ber., 29, 1585 (1896). Jordan, J. prakt. Chem., 10, 439 (1837).

${ }^{6}$ Horsford, Am. J. Sci., [2] 13, 305 (1852). Bauer, Ber., 4, 449 (1871). Guthrie, Phil. Mag., [5] 16, 321 (1883). Crookes, "Select Methods in Analytical Chemistry," 1894, p. 324 . Humphreys, J. Chem. Soc., 69, 243 (1896).

7 Treadwell-Hall, "Analytical Chemistry," John Wiley \& Sons, 1919, II, p. 194.

${ }^{8}$ Scott, "Standard Methods of Chemical Analysis," D. Van Nostrand, 1917, p. 271. 
There have been two physico-chemical methods used in research work on lead amalgams which are possibilities as means for determining the lead under certain conditions. Meyer, ${ }^{9}$ Richards and Forbes, ${ }^{10}$ and Wogau ${ }^{11}$ measured the electromotive force of lead amalgam concentration cells. Richards and Wilson ${ }^{12}$ determined the density of lead amalgams. When the magnitude of these physical quantities is a function of the concentration of the lead in the amalgam, it is possible to calculate the latter from the former.

In connection with certain work being done in this laboratory involving the use of electrolytically prepared lead amalgams, containing 30 to 50 g. of mercury and not over $0.5 \mathrm{~g}$. of lead, it became desirable to have available a method for determining the concentration of the lead which would be sufficiently accurate (involving an error of not over $0.05 \%$ ) and yet would not require complicated apparatus nor elaborate precautions, as is the case in making measurements of the electromotive force of easily oxidizable amalgams. All of the above methods seemed more or less objectionable for the work in hand, and the present paper is a report of a search for something more suitable.

\section{The Method Investigated}

It seemed desirable to find a method involving some process by means of which the lead could be brought easily from the amalgam into aqueous solution, without dissolving the relatively large amount of mercury, and then be determined gravimetrically in this solution. In an earlier paper $^{13}$ results were obtained which indicated the possibility of employing such a reaction as, $\mathrm{Pb} . \mathrm{Hg}+\mathrm{CuSO}_{4} \rightarrow \mathrm{Cu} . \mathrm{Hg}+\mathrm{PbSO}_{4}$. In this earlier work a galvanic cell was arranged according to the scheme, $\mathrm{Pb} . \mathrm{Hg} \mid \mathrm{Pb}$ $\mathrm{SO}_{4}\left\|\mathrm{CuSO}_{4} .5 \mathrm{H}_{2} \mathrm{O}\right\| \mathrm{Hg}_{2} \mathrm{SO}_{4} \mid \mathrm{Hg}$. When sodium sulfate decahydrate was used in a similar cell, the electromotive force was constant and reproducible at 0.96465 volts for $25^{\circ}$. With the copper salt, however, the average of the electromotive force obtained was 0.3487 volts for $25^{\circ}$. At that time it was assumed that the lead of the amalgam had displaced the copper and that the combination whose electromotive force was measured was essentially a cell of the form, $\mathrm{Cu} . \mathrm{Hg}\left|\mathrm{CuSO}_{4} .5 \mathrm{H}_{2} \mathrm{O}\right|\left|\mathrm{Hg}_{2} \mathrm{SO}_{4}\right| \mathrm{Hg}$. Later Oblata $^{14}$ measured the electromotive force of such a copper cell and obtained a value of 0.3466 volts for $25^{\circ}$, a result which seems to indicate the correctness of the above conclusions. The conditions in the two sets of experiments were not entirely the same which may account for the small disagreement in the results.

\footnotetext{
- Meyer, Z. physik. Chem., 7, 477 (1891).

${ }^{10}$ Richards and Forbes, Carnegie Inst. Pub., 56, 1 (1906).

11 Wogau, Ann. Physik, 23, 345 (1907).

12 Richards and Wilson, Carnegie Inst. Pub., 118, 1 (1909).

${ }_{18}$ Mellon and Henderson, This Journal, 42, 676 (1920).

14 Oblata, Proc, Phys. Math. Soc. Japan, [3] 2, 79, 223 (1920).
} 
A solution of copper nitrate $(1.035 M)$ was selected for the displacement of the lead in the amalgams. In the procedure adopted the amalgams were covered with $10 \mathrm{ml}$. of the solution. By stirring this solution well, the displacement of $0.4 \mathrm{~g}$. of lead was completed in 30 minutes at room temperature; but a number of hours is necessary if the stirring is omitted. The resulting solution was decanted and the remaining copper amalgam washed. Copper is less soluble than lead in mercury and in many of the determinations a considerable coating of brownish-red flakes collected on the surface of the mercury on standing for several hours in contact with the solution of copper nitrate. These flakes were found to be largely copper, along with some mercury, and the solution was always filtered from this material.

In obtaining the following data the various chemicals were purified as noted. The mercury was distilled by the familiar method of Hulett. Water for the preparation of solutions and the recrystallization of salts was redistilled from alkaline permanganate and from barium hydroxide. The salts were recrystallized twice. The solution of copper nitrate was found by an electrolytic analysis to be $1.035 \mathrm{M}$; that is $10 \mathrm{ml}$. contained $0.558 \mathrm{~g}$. of copper, equivalent to $2.14 \mathrm{~g}$. of lead. The lead was obtained as "silver-free" bars. It was first analyzed by precipitation as the sulfate. Near the end of the work a specimen of sheet lead was obtained from the Bureau of Standards which was stated to contain the following percentages of impurities: tin 0.03 , antimony 0.002 , copper 0.001 , iron 0.002 , nickel 0.001 , arsenic less than 0.0001 , and no silver, cobalt, zinc, bismuth, manganese or cadmium. Using the method developed in this paper, a careful determination was made of the amount of lead in this specimen, along with a similar determination for the silver-free bars. The four results are included in Table II as numbers 9,10,11 and 12 . All results were then calculated on the basis that the bars contained $99.96 \%$ lead. The amalgams were made by weighing carefully cleaned pieces of lead and dissolving them in the mercury (usually under water containing one drop of $10 \%$ acetic acid).

Precipitation of the Lead.-An attempt was first made to determine the lead in the solution obtained from the amalgam by precipitation with sulfuric acid. Amalgams containing known amounts of lead stood for 24 hours in contact with $15 \mathrm{ml}$. of the solution of copper nitrate. The solution was then decanted, a second portion of $5 \mathrm{ml}$. of the solution of copper ritrate was added, and allowed to stand in contact with the amalgam for 30 minutes. To the total, warm solution $5 \%$ sulfuric acid was added, the lead sulfate filtered on a Gooch crucible, and ignited for 15 minutes at a dull red heat. The weight of lead sulfate found was always about $0.8 \%$ too low. This was due to its solubility in the solution of copper nitrate, which was shown to be as high as $38 \mathrm{mg}$. in $40 \mathrm{ml}$. of $0.517 \mathrm{M}$ cupric nitrate solution.

Solubility of Lead Chromate in a Solution of Copper Nitrate.-In crder to ascertain the effect of copper nitrate on the determination of lead as the chromate, the concentration of a solution of lead nitrate was determined by precipitating the lead, in the presence of two drops of $10 \%$ 
acetic acid, with potassium dichromate, ${ }^{15}$ and drying the lead chromate at $120^{\circ}$ in a Gooch crucible. With the same volumes of solution, but with the addition of various amounts of copper nitrate, the results of Table I were obtained.

TABLE I

Solubility of lead Chromate in the Presence of Copper Nitrate

\begin{tabular}{|c|c|c|c|c|c|}
\hline & \multicolumn{3}{|c|}{ Composition of solution } & \multicolumn{2}{|l|}{$\mathrm{PbCrO}_{4}$} \\
\hline No. & $\mathrm{Pb}\left(\mathrm{NO}_{3}\right)_{2}$ & $\begin{array}{c}\mathrm{Cu}\left(\mathrm{NO}_{3}\right)_{2} \\
\mathrm{Ml}\end{array}$ & $\begin{array}{l}\mathrm{H}_{2} \mathrm{O} \\
\text { Ml. }\end{array}$ & $\begin{array}{l}\text { found } \\
\mathrm{G} \text {. }\end{array}$ & $\begin{array}{l}\text { Loss } \\
\%\end{array}$ \\
\hline 1 & 50 & (a) & 25 & 0.4808 & $\ldots$ \\
\hline 2 & 50 & $2^{a}$ & 23 & 0.4806 & 0.041 \\
\hline 3 & 50 & 5 & 20 & 0.4804 & 0.072 \\
\hline 4 & 50 & 10 & 15 & 0.4802 & 0.124 \\
\hline 5 & 50 & 15 & 10 & 0.4800 & 0.166 \\
\hline 6 & 50 & 25 & $\ldots$ & 0.4799 & 0.187 \\
\hline
\end{tabular}

a $1.035 M$ solution.

For increasing concentrations of copper nitrate these results show a rather definite decrease in the amount of lead chromate obtained. However, the loss is not large for the lower concentrations.

As the solubility of lead chromate is apparently very much less in the presence of copper nitrate than is that for lead sulfate, this method of precipitation was next tried. The results obtained are shown in Table II. They indicate that this procedure is satisfactory except for the most accurate work.

TABLE II

Determination of LeAd as Lead Chromate

\begin{tabular}{|c|c|c|c|c|c|}
\hline & & & & & \\
\hline & & Composition & amalgam & Lead & \\
\hline No. & Sample & $\begin{array}{l}\text { Mercury } \\
\text { G. }\end{array}$ & $\begin{array}{l}\text { Lead } \\
\text { G. }\end{array}$ & $\begin{array}{l}\text { found } \\
\mathrm{G} \text {. }\end{array}$ & $\begin{array}{c}\text { Variation } \\
\%\end{array}$ \\
\hline 1 & & $30-40$ & 0.2616 & 0.2615 & -0.04 \\
\hline 2 & & $30-40$ & 0.2763 & 0.2761 & -0.07 \\
\hline 3 & Com. sheet & $30-40$ & 0.3013 & 0.3014 & +0.03 \\
\hline 4 & & $30-40$ & 0.2751 & 0.2754 & +0.11 \\
\hline 5 & & 37.741 & 0.3445 & 0.3447 & +0.05 \\
\hline 6 & & 28.715 & 0.2752 & 0.2753 & +0.04 \\
\hline 7 & & 38.514 & 0.4054 & 0.4057 & +0.07 \\
\hline 8 & SIlver tree & 23.500 & 0.2161 & 0.2162 & +0.05 \\
\hline 9 & & $30-40$ & 0.3684 & 0.3683 & -0.027 \\
\hline 10 & & $30-40$ & 0.3942 & 0.3940 & -0.051 \\
\hline 11 & B Stds sheet & $30-40$ & 0.3879 & 0.3876 & -0.077 \\
\hline 12 & B. Stas, sheet & $30-40$ & 0.3828 & 0.3827 & -0.027 \\
\hline
\end{tabular}

Effect of Variable Factors upon the Displacement Reaction

Having found that the above procedure for determining lead in lead amalgam gave results averaging less than $0.1 \%$ error, a number of determinations were made in order to ascertain within what limits one might ${ }^{25}$ Ref. 8, p. 236. 
vary the arbitrary conditions previously maintained. The effect was studied of the factors, time, temperature, concentration of copper nitrate, and agitation upon the completion of the displacement reaction.

In general, the following procedure was carried out in the various experiments. Into a $100 \mathrm{ml}$. Nessler tube, $3 \mathrm{~cm}$. in diameter, a volume of water was measured sufficient to make a total of $50 \mathrm{ml}$. of solution after the addition of the copper nitrate. Approximately $35 \mathrm{~g}$. of mercury (weighed) was placed in the tube, followed by the lead. The tube was shaken to hasten the solution of the lead. A drop of $10 \%$ acetic acid was then added in order to prevent the development of a slight cloudiness after the addition of the lead. From this point the procedure varied somewhat, depending upon the particular factor being studied.

Time.--In the system under consideration there are two processes, in addition to the actual precipitation of the lead, requiring more or less time for their completion, (1) the solution of the lead in the mercury, and (2) the reaction between the lead and the copper nitrate.

The time necessary for lead to dissolve in mercury depends upon at least the temperature, the amounts of the two elements, the degree of sub-division of the lead, and the agitation of the system. Experiments showed that the lead was completely dissolved in the mercury after 1 hour, with occasional shaking, but not without it.

The next step was the determination of the time necessary, under given conditions, for the displacement reaction to go to completion. Completion was taken to be the point at which an amount of lead was recovered equal to that put into the mercury. A set of amalgams was prepared, all containing nearly the same weights of lead, and sufficient time allowed for the solution of the lead. They were stirred uniformly at $25^{\circ}$, after the addition of $10 \mathrm{ml}$. of the solution of copper nitrate to each tube. After various intervals of time, the aqueous solution was filtered off and the lead determined. The results of Table III show that the reaction was complete in 30 minutes.

TABLE III

\begin{tabular}{|c|c|c|c|c|}
\hline \multirow[b]{2}{*}{ No. } & \multicolumn{4}{|c|}{ EFFECT OF TIME ON THE DISPLACEMENT REACTION } \\
\hline & $\begin{array}{l}\text { Time } \\
\text { Min. }\end{array}$ & $\begin{array}{c}\text { Lead } \\
\text { taken } \\
\text { G. }\end{array}$ & $\begin{array}{c}\text { Lead } \\
\text { found } \\
G .\end{array}$ & $\begin{array}{c}\text { Variation } \\
\%\end{array}$ \\
\hline 1 & 15 & 0.3013 & 0.2898 & -3.82 \\
\hline 2 & 30 & 0.3015 & 0.3014 & -0.03 \\
\hline 3 & 60 & 0.3009 & 0.3010 & +0.03 \\
\hline 4 & 150 & 0.3006 & 0.3005 & -0.03 \\
\hline
\end{tabular}

Temperature and Concentration of Copper Nitrate.-The following results were obtained in the same manner as those for Table IIr. Using two temperatures and different concentrations of copper nitrate, the com- 
pletion of the reaction was determined at various intervals of time. Table IV shows the results for a typical run, made at $0.5^{\circ}$ for 30 minutes.

TABLE IV

\begin{tabular}{|c|c|c|c|c|c|c|}
\hline \multicolumn{7}{|c|}{ COMPLETION OF DISPLACEMENT REACTION AT $0.5^{\circ}$} \\
\hline & Aqueor & solution & Am & & Lead & \\
\hline No. & $\mathrm{H}_{2} \mathrm{O}$ & $\mathrm{Cu}\left(\mathrm{NO}_{3}\right)_{2}{ }^{a}$ & Mercury & Lead & found & Completion \\
\hline & $\begin{array}{l}\text { M1. } \\
48\end{array}$ & $\begin{array}{c}\text { Ml. } \\
2\end{array}$ & G. & $\stackrel{G}{G}$ & 0.9609 & 150 \\
\hline 1. & 48 & & 34.037 & 0.4003 & 0.0009 & \\
\hline 2 & 46 & 4 & 32.840 & 0.4007 & 0.1055 & 26.3 \\
\hline 3 & 44 & 6 & 35.428 & 0.4004 & 0.1528 & 38.1 \\
\hline 4 & 42 & 8 & 33.437 & 0.4008 & 0.1995 & 49.7 \\
\hline 5 & 40 & 10 & 34.677 & 0.4000 & 0.2584 & 64.6 \\
\hline
\end{tabular}

It was not found possible to obtain closely agreeing restlts for different runs. This might be predicted from the manner of making the determinations. For the runs at $25^{\circ}$ an average of the values has been taken. These are shown in Table V. The weights of lead varied from 0.4000 to $0.4008 \mathrm{~g}$, and the mercury from 30.740 to $36.641 \mathrm{~g}$.

TABLE V

COMPLETton OF Displacement Reaction for VARIOUS Conditions

$\begin{array}{ccccc}\text { No. } & \mathrm{Cu}\left(\mathrm{NO}_{3}\right)_{2}{ }^{a} & 15 \text { min. } & 30 \text { min. } & 60 \text { min. } \\ & \mathrm{Ml} . & \% & \% & \% \\ 1 & 2 & 22 & 38 & 62 \\ 2 & 3 & \ldots & 58 & \ldots \\ 3 & 4 & 46 & 79 & 99.5 \\ 4 & 5 & \ldots & 92 & \ldots \\ 5 & 6 & 66 & 96 & 100 \\ 6 & 8 & 84.6 & 99.6 & \ldots \\ 7 & 10 & 97.2 & 100 & \ldots\end{array}$

a In $50 \mathrm{ml}$. of total solution on amalgam.

In Fig. 1 is plotted concentration of copper nitrate (in ml. of a solution of $1.035 \mathrm{M}$ concentration) against the percentage completion of the reaction. The lowest curve is for $0.5^{\circ}$, while the other 3 are for $25^{\circ}$. The latter show the effect of time upon the reaction. It will be noted that the reaction is complete at 30 minutes for $10 \mathrm{ml}$. of the solution of copper nitrate, supporting the conclusion drawn from the results of Table III.

The curves have been extended to the intersection of the axes on the assumption that no displacement occurs at zero concentration of copper nitrate. It should not be inferred from this, however, that no precipitate would form on the addition of potassium dichromate to the system, for the amalgam is readily oxidized by it.

In Fig. 2 a different basis has been used, the percentage completion being plotted against the time for the various concentrations of copper nitrate. The assumption has been made here that no reaction occurs at 
zero time, and the curves have been extended to the intersection of the axes.

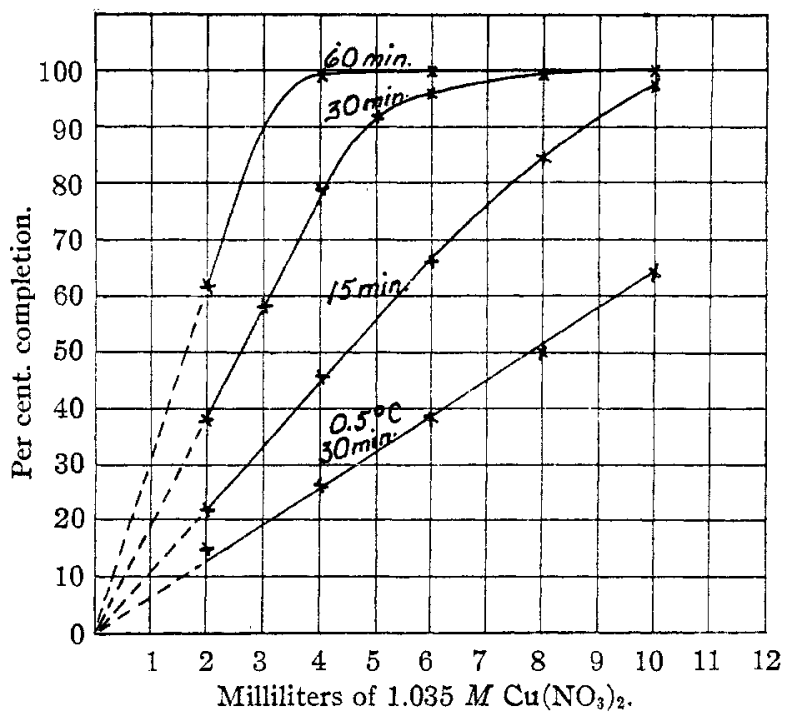

Fig. 1.-The completion of the displacement reaction for different concentrations of copper nitrate.

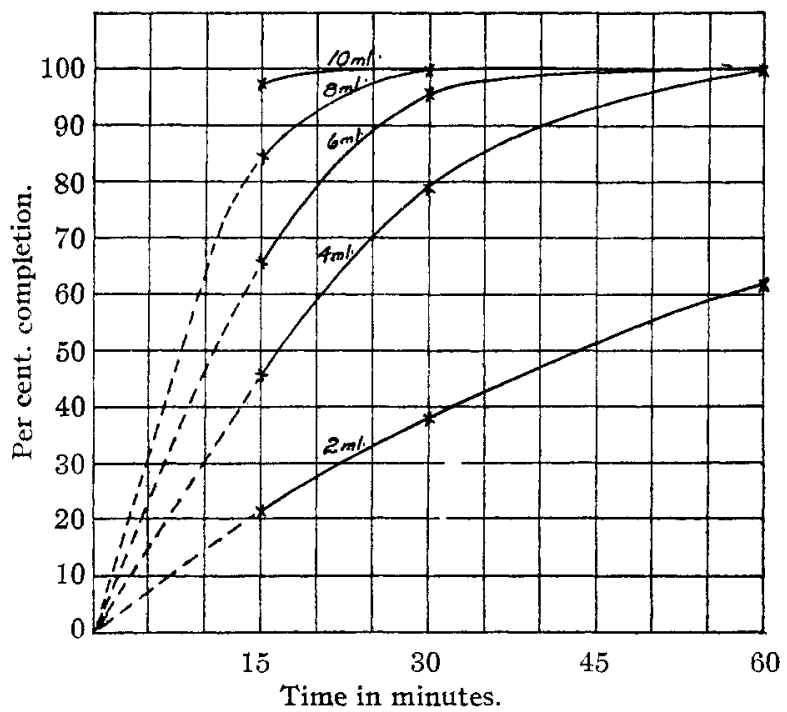

Fig. 2.-The completion of the displacement reaction at different intervals of time for various concentrations of copper nitrate. All determinations are for $25^{\circ}$.

Agitation.-Agitation of the amalgam has already been mentioned as hastening the process of solution of lead in the mercury. One would 
also expect agitation to produce a marked decrease in the time necessary for the completion of the displacement reaction, since diffusion in a quiet system is a relatively slow process. Only a few experiments were run bearing upon this particular point. The results in Table III show that, for a well stirred solution, the reaction is complete in 30 minutes using $10 \mathrm{ml}$. of the solution of copper nitrate. In other determinations where the conditions were approximately the same, except for no stirring after adding the solution of copper nitrate, the lead found ran $2-3 \%$ low after standing for about 4 hours.

Discussion.-The above procedure was developed for the specific purpose of determining the concentration of lead in lead amalgams which had been made electrolytically. Compared with other available methods, it possesses the advantage of being relatively simple and of avoiding the dissolving of the mercury, a necessity with other precipitation methods. In this case the mercury may be used again after purification. The accuracy obtainable seems to be satisfactory also except for the most refined work. The method might well be used when lead is being determined by deposition in a mercury cathode. It would avoid the liability for oxidation of the amalgam during drying and weighing, and also the necessity for determining the rather large weights of such cathodes.

For determining by this method up to $0.4 \mathrm{~g}$. of lead at ordinary room temperatures, the following procedure is recommended, assuming that the method of preparing the amalgam has afforded sufficient time for the solution of the lead in the mercury. Cover with water containing one drop of $10 \%$ acetic acid. Then add $10 \mathrm{ml}$. of a $1.0 \mathrm{M}$ solution of copper nitrate. Stir for at least 30 minutes, filter to remove any copper undissolved in the mercury, add another drop of acetic acid to the filtrate, and precipitate the lead under the usual conditions with potassium dichromate.

\section{Summary}

1. A résume is given of the principles of the methods which have been used previously for determining lead in lead amalgam.

2. Data are presented showing the possibility of making such a determination by displacement of the lead with copper from an aqueous solution of copper nitrate, followed by the precipitation of the lead as the chromate from the aqueous solution.

3 . The effects of such variables as time, temperature, concentration of copper nitrate, and agitation upon the completion of the displacement reaction, have been studied.

LAFAYETTE, INDLANA 